\title{
Use of Antidiabetic drugs during pregnancy among U.S. women with Livebirth deliveries in the Mini-Sentinel system
}

\author{
Katrina Mott ${ }^{1 *}$ (D), Marsha E. Reichman ${ }^{2}$, Sengwee Toh $^{3}$, Caren Kieswetter ${ }^{2}$, Katherine Haffenreffer ${ }^{3}$ and \\ Susan E. Andrade ${ }^{4}$
}

\begin{abstract}
Background: As the prevalence of diabetes mellitus increases in the population, the exposure to antidiabetic drugs (ADDs) during pregnancies is expected to grow, as has been seen over the last decade. The objective of this study was to estimate the prevalence of ADD use during pregnancy among women in the Mini-Sentinel Distributed Database (MSDD) who delivered a liveborn infant.

Methods: We identified qualifying livebirth pregnancies among women aged 10 to 54 years in the MSDD from 2001 to 2013. ADD use was estimated using outpatient pharmacy dispensing claims and days-supplied among three cohorts: all livebirth pregnancies, pregnancies among women with pre-existing diabetes, and pregnancies among women without prior ADD use.

Results: Among the 1.9 million pregnancies in the MSDD that resulted in a livebirth from 2001 to 2013, 4.4\% were exposed to an ADD. Of the 15,606 pregnancies (0.8\%) with pre-existing diabetes, $92.8 \%$ were also exposed during the pregnancy period. The most commonly used product in these pregnancies was insulin (75.6\% of pregnancies). In contrast, in pregnancies of women without prior ADD use, the most commonly used products were glyburide and insulin, and most of these users were diagnosed with gestational diabetes.

Conclusions: Patterns of ADD use during pregnancy described here, along with changes in disease incidence and management, highlight the importance of continuing surveillance of ADD utilization patterns and examining the safety and effectiveness of these products in pregnancy.
\end{abstract}

Keywords: Pregnancy, Glyburide, Insulin, Gestational diabetes

\section{Key points}

1. From 2001 to $2013,4.4 \%(n=82,676)$ of live birth pregnancies in the database were exposed to an antidiabetic drug (ADD).

2. Over the gestational period, increases in ADD use are mostly due to increases in use of two agents: glyburide and insulin.

3. Of pregnancies among women with pre-existing diabetes, 93\% were dispensed an ADD during the gestational period.

\footnotetext{
* Correspondence: kam417@mail.harvard.edu

${ }^{1}$ Department of Epidemiology, Harvard T.H. Chan School of Public Health, 677 Huntington Ave, Boston, MA, USA

Full list of author information is available at the end of the article
}

4. In pregnancies among women without prior ADD use, insulin and sulfonylureas were the most commonly used agents.

\section{Introduction}

There is a need for ongoing routine surveillance of medication use during pregnancy, as new drugs become available and prescribing trends and recommendations change. Up to $9 \%$ of pregnant women have pre-existing diabetes mellitus or develop gestational diabetes, which may require drug therapy [1-6]. The prevalence of gestational diabetes has been increasing over the last two decades [1-6]. Unmanaged diabetes in pregnancy, leading to hyperglycemia, is associated with excess risk of

(c) The Author(s). 2019 Open Access This article is distributed under the terms of the Creative Commons Attribution 4.0 International License (http//creativecommons.org/licenses/by/4.0/) which permits unrestricted use, distribution, and 
macrosomia, stillbirths, and other neonatal complications [7].

The American Congress of Obstetricians and Gynecologists (ACOG) Practice Bulletin \#30 in 2001 recommended adding insulin if glycemic control could not be achieved with nutritional therapy alone for women with gestational diabetes [8]. Several randomized controlled trials and observational studies, which compared glyburide to insulin for gestational diabetes, showed the two therapies to be comparable in achieving glycemic control [9]. In 2013, the ACOG guidelines were revised (Practice Bulletin \#137) to state that insulin and oral ADDs (e.g., glyburide and metformin) are equally efficacious, and could be considered for first-line therapy [9]. The use of glyburide increased during this time period [9]. The American Diabetes Association guidelines (2015) lists insulin and metformin as preferred treatments, and states that glyburide may be used, but may have a higher rate of neonatal hypoglycemia and macrosomia [10].

For women with pre-existing diabetes who become pregnant, an ACOG Practice Bulletin (\#60) in 2005 and a consensus statement by the American Diabetes Association in 2008 recommend insulin as the primary method of glycemic control [7, 11]. The ACOG guideline recommended stopping oral ADDs and switching to insulin as early in the pregnancy as possible [11].

The goal of this paper is to describe patterns of ADD use during pregnancy in the large cohort of livebirth pregnancies in the Mini-Sentinel Distributed Database (MSDD) from 2001 to 2013.

\section{Methods}

\section{Data source}

The U.S. Food and Drug Administration (FDA) MiniSentinel pilot project was a collaboration to build an active surveillance system for medical product safety [12]. This pilot project, which has now transitioned to the full-fledged Sentinel system, built a distributed database of insurance claims and administrative data using a common data model to create the MSDD. As of July 2014, the database included medical claims with procedure and diagnosis codes, pharmacy claims, and enrollment and demographic information for more than 178 million individuals. For this project, 15 data partners contributed to the analysis. The data partners performed standardized data analysis using an analytic tool developed by the Mini-Sentinel Operations Center and returned the summary-level results to the Operations Center for final aggregation and analysis. Data partners contributed data for varying time periods throughout the study period, with the majority of included pregnancies occurring after 2009. This project was conducted under FDA's public health authority and was not under the purview of the Institutional Review Board.

\section{Analytic tool}

This analysis utilized the Mini-Sentinel pregnancy analytic tool to identify women aged 10 to 54 years who delivered a liveborn infant between 2001 and 2013 [13]. It identified maternal characteristics of the eligible pregnancies, including year of delivery, maternal age, pre/ post-term birth, and pre-existing diabetes. To be included, women had to be enrolled in a health plan offered by an MSDD data partner which included medical and pharmacy benefits for at least 480 days prior to delivery. A woman could contribute multiple pregnancies if she met these criteria. Pregnancy periods, including trimesters, were calculated using a validated algorithm developed in the Medication Use in Pregnancy Risk Evaluation Program (MEPREP) and Post-Licensure Rapid Immunization Safety Monitoring (PRISM) projects to estimate gestational age at birth [14-16].

After cohort identification, the analytic tool determined medication exposure based on outpatient pharmacy dispensing claims for ADDs, identified by National Drug Code, during and prior to the pregnancy period. Exposure was defined using both dispense dates and days-supplied information in the MSDD. First trimester was defined as days 0 to 90 (with day 0 calculated as the estimated start of the pregnancy), the second trimester as days 91 to 180, and the third trimester as day 181 through the admit date of the hospital admission for delivery. All drug dispensing events were counted, so that a pregnancy could be counted in multiple drug exposure categories.

\section{Cohorts}

For this analysis, three cohorts were identified. First, the cohort of all eligible livebirth pregnancies was defined using the criteria described above to capture any qualifying livebirth pregnancy during the time period. Second, the cohort of pregnancies among women with preexisting diabetes was identified as any pregnancy for which the mother had a dispensing of a non-metformin ADD or a dispensing of metformin with a diabetes diagnosis code (ICD-9-CM 250.x) at any time in the 183 days prior to the start of pregnancy. We excluded metformin use that lacked a diabetes diagnosis code because metformin is also used to treat non-diabetic conditions, such as polycystic ovary syndrome. The third cohort consisted of pregnancies in women without any ADD dispensing in the 183 days prior to the start of pregnancy. To estimate the trends of ADD use for gestational diabetes, we identified pregnancies in the third cohort as women who were dispensed an ADD during the pregnancy period, and who met the following definition of gestational diabetes: a diagnosis code for gestational diabetes (ICD9-CM 648.8) in the 2nd or 3rd trimester and no prior diabetes mellitus diagnosis. 


\section{Statistical analysis}

In the three cohorts of pregnancies, we identified ADD use and specific agent use any time during pregnancy and by trimester. The percent of pregnancies with use of each product are presented to compare use across products, and through the pregnancy trimesters. We also stratified use by age group to identify differences in use patterns by maternal age. Prevalence ratios (PR) were calculated for the primary findings.

\section{Results}

The cohort of all livebirth pregnancies consisted of 1,895, 604 live birth pregnancies in 1.6 million women between 2001 and 2013, identified with the pregnancy algorithm in the MSDD (Table 1). For most pregnancies (58.3\%), women were between ages 25 to 34 at the time of delivery. Approximately $7.7 \%$ of deliveries had a code for

Table 1 Characteristics of the cohort of all livebirth pregnancies and the cohort of pregnancies among women with pre-existing diabetes between 2001 and 2013 in the MSDD

\begin{tabular}{|c|c|c|c|}
\hline Characteristic & & $\begin{array}{l}\text { Cohort of all livebirth } \\
\text { pregnancies }\end{array}$ & $\begin{array}{l}\text { Cohort of pregnancies } \\
\text { in women with } \\
\text { pre-existing diabetes }\end{array}$ \\
\hline $\begin{array}{l}\text { Total unique } \\
\text { women with } \\
\text { a pregnancy } \\
\text { episode }\end{array}$ & & $1,598,705$ & 14,216 \\
\hline $\begin{array}{l}\text { Total unique } \\
\text { pregnancies }\end{array}$ & & $1,895,604(100.00 \%)$ & 15,606 (100.00\%) \\
\hline $\begin{array}{l}\text { Total unique } \\
\text { pregnancies } \\
\text { with ADD }\end{array}$ & & $82,676(4.4 \%)$ & $14,488(92.8 \%)$ \\
\hline $\begin{array}{l}\text { Total unique } \\
\text { pregnancies } \\
\text { without ADD }\end{array}$ & & $1,812,928$ (95.6\%) & $1118(7.2 \%)$ \\
\hline $\begin{array}{l}\text { Maternal age at } \\
\text { delivery, years }\end{array}$ & $\begin{array}{l}<20 \\
20-24 \\
25-29 \\
30-34 \\
35-39 \\
40-44 \\
45-54\end{array}$ & $\begin{array}{l}115,584(6.1 \%) \\
260,013(13.7 \%) \\
495,250(26.1 \%) \\
610,703(32.2 \%) \\
329,080(17.4 \%) \\
76,995(4.1 \%) \\
7979(0.4 \%)\end{array}$ & $\begin{array}{l}404(2.6 \%) \\
1608(10.3 \%) \\
3545(22.7 \%) \\
4949(31.7 \%) \\
3745(24.0 \%) \\
1082(6.9 \%) \\
273(1.8 \%)\end{array}$ \\
\hline Year of delivery & $\begin{array}{l}2001 \\
2002 \\
2003 \\
2004 \\
2005 \\
2006 \\
2007 \\
2008 \\
2009 \\
2010 \\
2011 \\
2012 \\
2013\end{array}$ & $\begin{array}{l}41,870(2.21 \%) \\
62,345(3.29 \%) \\
62,310(3.29 \%) \\
61,544(3.25 \%) \\
64,573(3.41 \%) \\
68,056(3.59 \%) \\
122,674(6.47 \%) \\
146,443(7.73 \%) \\
246,203(12.99 \%) \\
275,835(14.55 \%) \\
263,694(13.91 \%) \\
252,272(13.31 \%) \\
227,785(12.02 \%)\end{array}$ & $\begin{array}{l}245(1.57 \%) \\
4.62(2.96 \%) \\
492(3.15 \%) \\
585(3.75 \%) \\
581(3.72 \%) \\
626(4.01 \%) \\
1040(6.66 \%) \\
1271(8.14 \%) \\
1946(12.47 \%) \\
2330(14.93 \%) \\
2132(13.66 \%) \\
2107(13.50 \%) \\
1789(11.46 \%)\end{array}$ \\
\hline $\begin{array}{l}\text { Any code for } \\
\text { preterm birth }\end{array}$ & & $146,523(7.7 \%)$ & $3108(19.9 \%)$ \\
\hline $\begin{array}{l}\text { Any code for } \\
\text { postterm birth }\end{array}$ & & $259,572(13.7 \%)$ & $309(2.0 \%)$ \\
\hline
\end{tabular}

preterm birth, while $13.7 \%$ had a code for post-term birth. Of the total cohort, $4.4 \%(n=82,676)$ of pregnancies had exposure to an ADD. Table 2 displays the use of ADD products by trimester in the total pregnancy cohort. Use of any ADD increased from the 1st to 3rd trimester ( 2.1 to $3.4 \%$ of pregnancies, prevalence ratio $=$ $1.59,95 \% \mathrm{CI}(1,57,1.61))$. This increase was due primarily to an increase in use of glyburide $(0.1$ to $1.4 \%, \mathrm{PR}=$ $13.91,95 \% \mathrm{CI}(13.27,14.57))$ and increase in use of insulin $(0.7$ to $1.8 \%, \mathrm{PR}=2.72,95 \% \mathrm{CI}(2.67,2.78))$ over the course of the pregnancy period. In the 90 days before pregnancy, $1.6 \%$ of pregnancies had exposure to metformin, but use of metformin decreased to $0.5 \%$ by the 3 rd trimester. As expected, exposure to ADDs increased with increasing maternal age (Table 3). The trend was similar for the three drug categories with the most use (metformin, sulfonylureas, and insulin).

There were 15,606 pregnancies among women with pre-existing diabetes, of which $92.8 \%$ had an ADD exposure during the pregnancy (Table 4). Compared to all livebirth pregnancies, pregnancies with pre-existing diabetes were more likely to be among older women $(32.7 \%$ of the pre-existing diabetes cohort vs. $21.9 \%$ of the total cohort was over age 35), and were more likely to have a pre-term birth (19.9\% vs. $7.7 \%)$ (Table 1$)$. In this cohort of women with pre-existing diabetes, the prevalence of ADD use remained steady over the course of pregnancy (85.4, 82.5, and $83.4 \%$ in each successive trimester, respectively), as shown in Table 4 . The most commonly used product during pregnancy was insulin $(75.6 \%$ of pregnancies), followed by metformin as the second most commonly used product $(37.7 \%) \quad(\mathrm{PR}=2.00,95 \% \mathrm{CI}$ (1.96, 2.05), Fig. 1). Metformin use among these pregnancies decreased over the course of pregnancy, from $35.7 \%$ in the first trimester to $14.5 \%$ in the third trimester (Table 4, Fig. 1). Sulfonylureas were also commonly used: glyburide at any time in $12.8 \%$ of pregnancies $(n=$ $2001)$ and consistently across trimesters $(7.0 \%$ of pregnancies in the 1 st trimester to $8.1 \%$ in the $3 \mathrm{rd}$ ), and glipizide at any time in $3.8 \%$ of pregnancies. Notably, pre-term delivery was more common among women with pre-existing diabetes $(19.9 \%$ vs. $7.7 \%$ in total cohort), so the third trimesters would, on average, be shorter than the second and first trimesters -- effectively having fewer days on which a prescription could be filled. There are large differences in the distribution of drugs used by maternal age group in this cohort (Table 5). The proportion of pregnancies exposed to metformin was more than twice as high in women over age 40 compared to the proportion in women under age $25(\mathrm{PR}=2.82,95 \% \mathrm{CI}(2.56,3.13))$. Similarly, the proportion of pregnancies exposed to a sulfonylurea was 30\% over age 45 , compared to less than $7 \%$ in pregnancies in women under age 20. Between 70 and $80 \%$ of 
Table 2 Antidiabetic Drug use, by trimester, in the cohort of all livebirth pregnancies during 2001-2013 in the MSDD

\begin{tabular}{|c|c|c|c|c|c|}
\hline & $\begin{array}{l}\text { Use in the } 90 \text { Days } \\
\text { Before Pregnancy }\end{array}$ & $\begin{array}{l}\text { Any Use During } \\
\text { Pregnancy }\end{array}$ & $\begin{array}{l}\text { Any Use, First } \\
\text { Trimester }\end{array}$ & $\begin{array}{l}\text { Any Use, Second } \\
\text { Trimester }\end{array}$ & $\begin{array}{l}\text { Any Use, Third } \\
\text { Trimester }\end{array}$ \\
\hline Total unique pregnancies & $1,895,604(100 \%)$ & $1,895,604(100 \%)$ & $1,895,604(100 \%)$ & $1,895,604(100 \%)$ & $1,895,122(100 \%)$ \\
\hline \multicolumn{6}{|l|}{ Drug Class or Product } \\
\hline Use of Any Drug & 38,017 (2.0\%) & $82,676(4.4 \%)$ & $40,013(2.1 \%)$ & $35,587(1.9 \%)$ & $63,483(3.4 \%)$ \\
\hline Alpha-Glucosidase Inhibitors & $21(<0.1 \%)$ & $149(<0.1 \%)$ & $19(<0.1 \%)$ & $24(<0.1 \%)$ & $129(<0.1 \%)$ \\
\hline Amylin Analog & $55(<0.1 \%)$ & $48(<0.1 \%)$ & $46(<0.1 \%)$ & $9(<0.1 \%)$ & $5(<0.1 \%)$ \\
\hline Metformin & $30,194(1.6 \%)$ & $32,757(1.7 \%)$ & $29,431(1.6 \%)$ & $15,827(0.8 \%)$ & $9897(0.5 \%)$ \\
\hline Dipeptidyl Peptidase-4 Inhibitors & $226(<0.1 \%)$ & $242(<0.1 \%)$ & $227(<0.1 \%)$ & $87(<0.1 \%)$ & $50(<0.1 \%)$ \\
\hline Glucagon-like Peptide-1 Agonists & $403(<0.1 \%)$ & $333(<0.1 \%)$ & $316(<0.1 \%)$ & $77(<0.1 \%)$ & $32(<0.1 \%)$ \\
\hline Meglitinide Analogs & $45(<0.1 \%)$ & $44(<0.1 \%)$ & $43(<0.1 \%)$ & $12(<0.1 \%)$ & $2(<0.1 \%)$ \\
\hline Sulfonylureas - Use of Any Drug & $2018(0.1 \%)$ & $28,240(1.5 \%)$ & $2748(0.1 \%)$ & $6325(0.3 \%)$ & $26,234(1.4 \%)$ \\
\hline Glimepiride & $312(<0.1 \%)$ & $280(<0.1 \%)$ & $255(<0.1 \%)$ & $97(<0.1 \%)$ & $61(<0.1 \%)$ \\
\hline Glipizide & $675(<0.1 \%)$ & $768(<0.1 \%)$ & $617(<0.1 \%)$ & $316(<0.1 \%)$ & $218(<0.1 \%)$ \\
\hline Glyburide & $976(0.1 \%)$ & $27,269(1.4 \%)$ & $1868(0.1 \%)$ & $5905(0.3 \%)$ & $25,973(1.4 \%)$ \\
\hline Tolazamide & $80(<0.1 \%)$ & $82(<0.1 \%)$ & $82(<0.1 \%)$ & $53(<0.1 \%)$ & $23(<0.1 \%)$ \\
\hline Thiazolidinediones & $965(0.1 \%)$ & $874(0.1 \%)$ & $841(<0.1 \%)$ & $274(<0.1 \%)$ & $123(<0.1 \%)$ \\
\hline Combination Products & $565(<0.1 \%)$ & $633(<0.1 \%)$ & $520(<0.1 \%)$ & $204(<0.1 \%)$ & $155(<0.1 \%)$ \\
\hline Insulin - Any Injectable Insulin & $7351(0.4 \%)$ & $34,476(1.8 \%)$ & $12,289(0.7 \%)$ & $18,028(0.9 \%)$ & $33,447(1.8 \%)$ \\
\hline Rapid-acting & $5842(0.3 \%)$ & $25,959(1.4 \%)$ & $10,074(0.5 \%)$ & $14,602(0.8 \%)$ & $24,705(1.3 \%)$ \\
\hline Intermediate-acting & $1803(0.1 \%)$ & $26,103(1.4 \%)$ & $6607(0.4 \%)$ & $11,824(0.6 \%)$ & $24,745(1.3 \%)$ \\
\hline Long-acting & $2394(0.1 \%)$ & $4834(0.3 \%)$ & $2846(0.2 \%)$ & $2791(0.2 \%)$ & $3436(0.2 \%)$ \\
\hline Other-acting & $598(<0.1 \%)$ & $1556(0.1 \%)$ & $854(0.1 \%)$ & $794(0.1 \%)$ & $976(0.1 \%)$ \\
\hline
\end{tabular}

pregnancies in women under age 45 with pre-existing diabetes were exposed to insulin.

Among pregnancies without prior use of any ADD in the 183 days before last menstrual period (LMP), the most commonly used ADDs in pregnancy were sulfonylureas, followed by insulin and metformin (Fig. 2). In this cohort, as expected for gestational diabetes, exposure to ADDs increased over the course of pregnancy with most use occurring in the 3rd trimester when the diagnosis is made (reflected by the use of sulfonylureas and insulin). However, a proportion of pregnancies without prior use of any ADD did not meet both criteria of our gestational

Table 3 Antidiabetic Drug use, by maternal age, in all livebirth pregnancies during 2001-2013 in the MSDD

\begin{tabular}{|c|c|c|c|c|c|c|c|}
\hline & $<20$ years & 20-24 years & $25-29$ years & 30-34 years & $35-39$ years & 40-44 years & $45-54$ years \\
\hline Total unique pregnancies & $115,584(100 \%)$ & $260,013(100 \%)$ & $495,250(100 \%)$ & $610,703(100 \%)$ & $329,080(100 \%)$ & 76,995 (100\%) & $7979(100 \%)$ \\
\hline \multicolumn{8}{|l|}{ Drug product/Class } \\
\hline Any Antidiabetic Drug & $1004(0.87 \%)$ & $5227(2.01 \%)$ & $18,775(3.79 \%)$ & $30,327(4.97 \%)$ & $20,788(6.32 \%)$ & $5874(7.63 \%)$ & $681(8.53 \%)$ \\
\hline Alpha-Glucosidase Inhibitors & $4(0.00 \%)$ & $10(0.00 \%)$ & $31(0.01 \%)$ & $54(0.01 \%)$ & $30(0.01 \%)$ & $18(0.02 \%)$ & $2(0.03 \%)$ \\
\hline Amylin Analog & $1(0.00 \%)$ & $4(0.00 \%)$ & $15(0.00 \%)$ & $19(0.00 \%)$ & $6(0.00 \%)$ & $3(0.00 \%)$ & $0(0.00 \%)$ \\
\hline Metformin & $294(0.25 \%)$ & 1839 (0.71\%) & $8616(1.74 \%)$ & $12,809(2.10 \%)$ & 7238 (2.20\%) & $1687(2.19 \%)$ & $274(3.43 \%)$ \\
\hline Dipeptidyl Peptidase-4 Inhibitors & $1(0.00 \%)$ & $4(0.00 \%)$ & $34(0.01 \%)$ & $69(0.01 \%)$ & $83(0.03 \%)$ & $30(0.04 \%)$ & $21(0.26 \%)$ \\
\hline $\begin{array}{l}\text { Glucagon-like Peptide-1 Receptor } \\
\text { Agonists }\end{array}$ & $4(0.00 \%)$ & $12(0.00 \%)$ & $58(0.01 \%)$ & $109(0.02 \%)$ & $98(0.03 \%)$ & $36(0.05 \%)$ & $16(0.20 \%)$ \\
\hline Meglitinide Analogs & $1(0.00 \%)$ & $8(0.00 \%)$ & $8(0.00 \%)$ & $13(0.00 \%)$ & $9(0.00 \%)$ & $3(0.00 \%)$ & $2(0.03 \%)$ \\
\hline Sulfonylureas & $237(0.21 \%)$ & $1452(0.56 \%)$ & $5542(1.12 \%)$ & $10,151(1.66 \%)$ & 8012 (2.43\%) & $2570(3.34 \%)$ & 276 (3.46\%) \\
\hline Thiazolidinediones & $17(0.01 \%)$ & $69(0.03 \%)$ & $208(0.04 \%)$ & $268(0.04 \%)$ & $196(0.06 \%)$ & 73 (0.09\%) & $43(0.54 \%)$ \\
\hline Combination Products & 10 (0.01\%) & 55 (0.02\%) & $117(0.02 \%)$ & $197(0.03 \%)$ & $177(0.05 \%)$ & $52(0.07 \%)$ & $25(0.31 \%)$ \\
\hline Insulin & $590(0.51 \%)$ & 2562 (0.99\%) & 6986 (1.41\%) & 11,868 (1.94\%) & 9392 (2.85\%) & $2813(3.65 \%)$ & 265 (3.32\%) \\
\hline
\end{tabular}


Table 4 Antidiabetic drug use, by trimester, in livebirth pregnancies among women with pre-existing diabetes during 2001-2013 in the MSDD

\begin{tabular}{|c|c|c|c|c|c|}
\hline & $\begin{array}{l}\text { Use in the } 90 \text { Days } \\
\text { Before Pregnancy }\end{array}$ & $\begin{array}{l}\text { Any Use During } \\
\text { Pregnancy }\end{array}$ & $\begin{array}{l}\text { Any Use, First } \\
\text { Trimester }\end{array}$ & $\begin{array}{l}\text { Any Use, Second } \\
\text { Trimester }\end{array}$ & $\begin{array}{l}\text { Any Use, Third } \\
\text { Trimester }\end{array}$ \\
\hline Total unique pregnancies & $15,606(100 \%)$ & $15,606(100 \%)$ & $15,606(100 \%)$ & $15,606(100 \%)$ & $15,594(100 \%)$ \\
\hline \multicolumn{6}{|l|}{ Drug Product/Class } \\
\hline Use of Any Drug & 13,847 (88.7\%) & $14,488(92.8 \%)$ & $13,322(85.4 \%)$ & $12,876(82.5 \%)$ & $12,998(83.4 \%)$ \\
\hline Metformin & 6024 (38.6\%) & $5886(37.7 \%)$ & 5572 (35.7\%) & $3533(22.6 \%)$ & $2257(14.5 \%)$ \\
\hline Sulfonylureas - Any Drug & 2018 (12.9\%) & $2803(18.0 \%)$ & $1916(12.3 \%)$ & $1532(9.8 \%)$ & $1414(9.1 \%)$ \\
\hline Glipizide & $675(4.3 \%)$ & $596(3.8 \%)$ & $573(3.7 \%)$ & $270(1.7 \%)$ & $91(0.6 \%)$ \\
\hline Glyburide & $976(6.3 \%)$ & $2001(12.8 \%)$ & $1097(7.0 \%)$ & $1162(7.5 \%)$ & $1268(8.1 \%)$ \\
\hline Thiazolidinediones & $965(6.2 \%)$ & $800(5.1 \%)$ & 786 (5.0\%) & $258(1.7 \%)$ & $104(0.7 \%)$ \\
\hline Combination Products & $565(3.6 \%)$ & $502(3.2 \%)$ & $480(3.1 \%)$ & $166(1.1 \%)$ & $73(0.5 \%)$ \\
\hline Insulin & 7351 (47.1\%) & $11,796(75.6 \%)$ & $9625(61.7 \%)$ & $10,776(69.1 \%)$ & $11,328(72.6 \%)$ \\
\hline
\end{tabular}

diabetes algorithm definition: a diagnosis code for gestational diabetes in the 2nd or 3rd trimester and no prior diabetes mellitus diagnosis $(5.8 \%$ of sulfonylureaexposed pregnancies, $14.4 \%$ of insulin-exposed pregnancies, and $50.2 \%$ of metformin-exposed pregnancies).

\section{Discussion}

In the MSDD cohort of livebirth pregnancies from 2001 to 2013, 4.4\% were exposed to an ADD during pregnancy. Use of insulin and glyburide increased in prevalence over the pregnancy period, which is likely due to a combination of newly diagnosed gestational diabetes and a switch to these treatments from other oral drugs among women with pre-existing diabetes. In pregnancies among the women who might have gestational diabetes based on their ADD use pattern (i.e. no ADD use prior to pregnancy with ADD initiation during pregnancy), not all of the women met our gestational diabetes definition based on the algorithm described above. We suspect two possible explanations account for the women not meeting the definition: 1) they had untreated diabetes mellitus prior to pregnancy and were started on ADD therapy during pregnancy. Therefore, the algorithm appropriately excluded these women from being assigned a gestational diabetes indicator; or 2) they were clinically diagnosed and treated for gestational diabetes

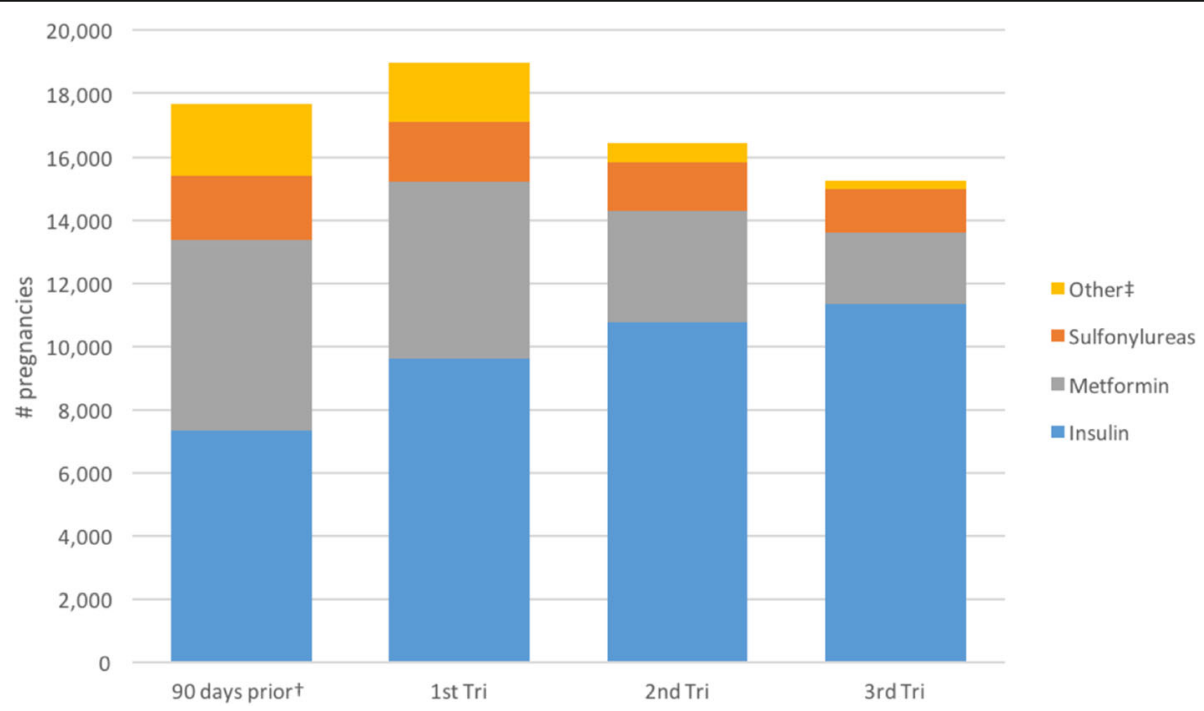

Fig. 1 Antidiabetic drug use, by trimester, in the cohort of pregnancies among women with pre-existing diabetes during 2001-2013 in the MSDD. +90 days prior is the period of 90 days prior to the calculated start of pregnancy based on the pregnancy period algorithm using livebirth delivery claim codes. 1st Tri, 2nd Tri, and 3rd Tri refer to the gestational trimesters, also calculated using the pregnancy period algorithm based on delivery codes. Individual pregnancies could be counted in multiple gestational terms and for multiple drug categories. $\neq$ Other category includes alpha-glucosidase inhibitors, meglitinide analogs, amylin analog, DPP-4 inhibitors, GLP-1 receptor agonists, thiazolidinediones, and combination products 
Table 5 Antidiabetic drug use, by maternal age, in livebirth pregnancies among women with pre-existing diabetes during 20012013 in the MSDD

\begin{tabular}{|c|c|c|c|c|c|c|c|}
\hline & $<20$ years & 20-24 years & $25-29$ years & 30-34 years & $35-39$ years & 40-44 years & 45-54 years \\
\hline Total unique pregnancies & $404(100 \%)$ & $1608(100 \%)$ & $3545(100 \%)$ & 4949 (100\%) & $3745(100 \%)$ & $1082(100 \%)$ & $273(100 \%)$ \\
\hline \multicolumn{8}{|l|}{ Drug product/Class } \\
\hline Any Antidiabetic Drug & $365(90.35 \%)$ & 1419 (88.25\%) & $3262(92.02 \%)$ & $4635(93.66 \%)$ & $3536(94.42 \%)$ & $1010(93.35 \%)$ & $261(95.60 \%)$ \\
\hline Alpha-Glucosidase Inhibitors & $0(0.00 \%)$ & $2(0.12 \%)$ & $8(0.23 \%)$ & $9(0.18 \%)$ & $3(0.08 \%)$ & $4(0.37 \%)$ & $2(0.73 \%)$ \\
\hline Amylin Analog & $1(0.25 \%)$ & $3(0.19 \%)$ & $14(0.39 \%)$ & $17(0.34 \%)$ & $6(0.16 \%)$ & $3(0.28 \%)$ & $0(0.00 \%)$ \\
\hline Metformin & $87(21.53 \%)$ & $311(19.34 \%)$ & 1102 (31.09\%) & 1906 (38.51\%) & $1722(45.98 \%)$ & $598(55.27 \%)$ & $160(58.61 \%)$ \\
\hline Dipeptidyl Peptidase-4 Inhibitors & $1(0.25 \%)$ & $3(0.19 \%)$ & $32(0.90 \%)$ & $66(1.33 \%)$ & $75(2.00 \%)$ & $27(2.50 \%)$ & 19 (6.96\%) \\
\hline $\begin{array}{l}\text { Glucagon-like Peptide-1 Receptor } \\
\text { Agonists }\end{array}$ & $3(0.74 \%)$ & $11(0.68 \%)$ & $56(1.58 \%)$ & $103(2.08 \%)$ & $94(2.51 \%)$ & $34(3.14 \%)$ & $15(5.49 \%)$ \\
\hline Meglitinide Analogs & $1(0.25 \%)$ & $7(0.44 \%)$ & $8(0.23 \%)$ & $13(0.26 \%)$ & $9(0.24 \%)$ & $3(0.28 \%)$ & $2(0.73 \%)$ \\
\hline Sulfonylureas & $28(6.93 \%)$ & $184(11.44 \%)$ & $512(14.44 \%)$ & $907(18.33 \%)$ & $833(22.24 \%)$ & 255 (23.57\%) & $84(30.77 \%)$ \\
\hline Thiazolidinediones & $14(3.47 \%)$ & $64(3.98 \%)$ & $181(5.11 \%)$ & $246(4.97 \%)$ & $187(4.99 \%)$ & $68(6.28 \%)$ & $40(14.65 \%)$ \\
\hline Combination Products & $6(1.49 \%)$ & $37(2.30 \%)$ & $84(2.37 \%)$ & $155(3.13 \%)$ & $155(4.14 \%)$ & 43 (3.97\%) & $22(8.06 \%)$ \\
\hline Insulin & $321(79.46 \%)$ & 1237 (76.93\%) & 2701 (76.19\%) & 3767 (76.12\%) & 2868 (76.58\%) & 789 (72.92\%) & $113(41.39 \%)$ \\
\hline
\end{tabular}

but a claim with the gestational diabetes diagnosis code was not filed with their insurance. Errors in coding or claims may also be responsible for some proportion of this discrepancy.

Many of the findings in this analysis were similar to those of previous work, particularly in the MEPREP database [17]. Specifically, the proportion of pregnancies with metformin, glyburide, and insulin exposure were comparable in the two studies. This similarity is expected, since 8 out of the 15 data partners in this analysis also participated in MEPREP. In the cohort of women with pre-existing diabetes in this study, at least $83 \%$ of pregnancies were exposed to an ADD in the second or third trimester, in contrast to the $56.5 \%$ reported by MEPREP although different definitions of prior ADD exposure were used. The MEPREP study included ADD use within 120 days prior to pregnancy and may have included women using metformin for reasons other than glycemic control who would not be expected to continue use during pregnancy [17].

The major strengths of this study are the size of the pregnancy cohort and the ability to define sub-cohorts based on prior diagnoses or prescriptions dispensed. The database consists of mostly privately insured individuals, so the findings may be generalized to the broader population of women with commercial insurance in the U.S.

Some of the limitations of this study are as follows. As with any claims-based surveillance of prescription drug

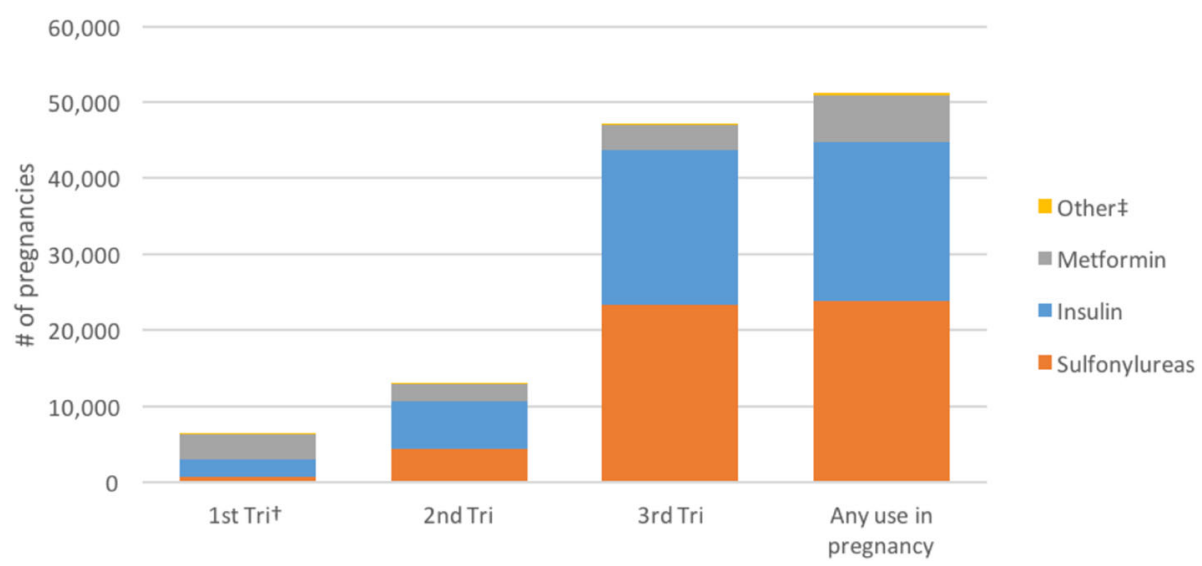

Fig. 2 Antidiabetic drug use, by trimester, in the cohort of pregnancies among women with no prior ADD use during 2001-2013 in the MSDD. + 1st Tri, 2nd Tri, and 3rd Tri refer to the three gestational trimesters, calculated using the pregnancy period algorithm based on delivery codes. Individual pregnancies could be counted in multiple gestational terms and for multiple drug categories. ₹ Other category includes alphaglucosidase inhibitors, meglitinide analogs, amylin analog, DPP-4 inhibitors, GLP-1 receptor agonists, thiazolidinediones, and combination products 
use, this study assumed that prescriptions dispensed were taken by the women. Exposure was defined by the days supplied from each dispensing. Additionally, pregnancies were counted in every drug category to which they were exposed, but this study did not determine how many pregnancies were exposed to multiple medications, or the reason for changes in treatment. Furthermore, the results are limited to the pregnancies with a livebirth outcome, and do not include exposures in women who had miscarriages, stillbirths, or terminations. At the time of this study, we were unable to define women's parity. Out-of-pocket payments for prescriptions are not recorded in claims data and are a source of missing data. The definition for pre-gestational diabetes is not validated, and misclassification of diabetes status is possible. Finally, data partners contributed data for different time periods, with most contributing data for recent years, so these estimates most closely reflect use in the 20072013 time period. This limitation means we could not analyze trends robustly over time, although some general observations are similar to the trends others have described in similar populations $[17,18]$. Among all livebirth pregnancies in our study, the use of glyburide increased over this time period studied, from less than $0.5 \%$ of pregnancies to approximately $2 \%$; this increase was not seen in pregnancies among women with preexisting diabetes (data not shown). For women with preexisting diabetes, the prevalence of metformin use has increased ( 20.4 to $41.5 \%$ ) over the study period, while use of insulin decreased (89.8 to $77.3 \%$ ). Interpreting these trends requires the assumption that the women enrolled in the databases contributing data in the early years are similar to the women enrolled in the contributing databases in recent years, which may not be a valid assumption.

The rates of diabetes mellitus and gestational diabetes have increased over the last two decades $[1,2,4,6,19]$. Obstetric practice recommendations in the treatment of gestational diabetes has also changed, as noted by others and as reflected in updated guidelines [8, 11, 18]. These trends suggest that a larger proportion of pregnancies are likely exposed to antidiabetic drugs in the coming years. Changes in disease incidence and management highlight the need for continuing surveillance of ADD utilization patterns and examining the safety and effectiveness of these products in pregnancy.

\section{Conclusions}

This study finds that from 2001 to 2013, 4.4\% of pregnancies were exposed to an antidiabetic drug. Almost all pregnancies among women with pre-existing diabetes continue treatment during the pregnancy, with $75 \%$ being treated with insulin. Among pregnancies in women without pre-existing diabetes, sulfonylureas (particularly glyburide) and insulin were the most commonly used products to treat gestational diabetes. This observational cohort of pregnancies receiving ADD treatment highlight the importance of continuing surveillance of ADD utilization patterns and examining drug safety and effectiveness among pregnant women.

\section{Abbreviations}

ACIP: Advisory Committee on Immunization Practices; ACOG: American College of Obstetricians and Gynecologists; ADD: Antidiabetic drug; FDA: Food and Drug Administration; ICD-9: International Classification of Diseases, Ninth Edition; LMP: Last menstrual period; MEPREP: Medication Use in Pregnancy Risk Evaluation Program; MSDD: Mini-Sentinel Distributed Database; PR: Prevalence ratio; PRISM: Post-Licensure Rapid Immunization Safety Monitoring

\section{Acknowledgements}

This study was presented, in part, as a poster at the 2015 International Conference on Pharmacoepidemiology \& Therapeutic Risk Management, in Boston, MA, August 2015. Many thanks are due to those who participated in this project: Data Partners who provided data used in the analysis: Aetna, a CVS Health company, Blue Bell, PA; Harvard Pilgrim Health Care Institute, Boston, MA; HealthCore, Inc., Translational Research for Affordability and Quality, Alexandria, VA; HealthPartners Institute, Minneapolis, Minnesota; Humana, Inc., Healthcare Research, Miramar, FL; Kaiser Permanente Colorado Institute for Health Research, Denver, CO; Kaiser Permanente Center for Health Research Hawai'i, Honolulu, HI; Kaiser Permanente Mid-Atlantic States, Mid-Atlantic Permanente Research Institute, Rockville, MD; Kaiser Permanente Northern California, Division of Research, Oakland, CA; Kaiser Permanente Northwest Center for Health Research, Portland, OR; Kaiser Permanente Washington Health Research Institute, Seattle, WA; Marshfield Clinic Research Institute, Marshfield, WI; Meyers Primary Care Institute, Worcester, MA; OptumInsight Life Sciences Inc., Boston, MA; Vanderbilt University Medical Center, Department of Health Policy, Nashville, TN, through the TennCare Division of the Tennessee Department of Finance \& Administration which provided data. The views expressed in this paper are those of the authors and are not intended to convey official U.S. Food and Drug Administration (FDA) policy or guidance.

\section{Authors' contributions}

KM and MER contributed to the writing of the manuscript and interpretation of the data. SE and ST made substantial contributions to the study design, analysis of the data and critical revision of the manuscript. $\mathrm{KH}$ was

fundamental in the acquisition of the data and contributed to interpretation of the data and critical revision of the manuscript. CK provided clinical expertise during the study design, data analysis, and manuscript revision. All authors gave approval for final publication of the manuscript.

\section{Funding}

This study was supported through funding from contract HHSF223200910006I, Task Order \# HHSF22301007T from the U.S. Food and Drug Administration (FDA). Co-authors from the FDA provided input on the study design and analysis plan, interpreting results, and preparing the manuscript for publication. The FDA reviewed and approved this manuscript. The FDA had no role in data collection or management.

This project was supported in part by an appointment to the ORISE Research Participation Program at the Center for Drug Evaluation and Research administered by the Oak Ridge Institute for Science and Education through an agreement between the U.S. Department of Energy and CDER.

\section{Availability of data and materials}

The datasets used and/or analyzed during the current study are available from the corresponding author on reasonable request.

\section{Ethics approval and consent to participate}

This project was conducted under FDA's public health authority and as such was not under the purview of the Institutional Review Board.

\section{Consent for publication}

N/A 


\section{Competing interests}

KM, MER, ST, CK, KH have no competing interests to report. SEA has received grant support from Pfizer Inc.

\section{Author details}

'Department of Epidemiology, Harvard T.H. Chan School of Public Health, 677 Huntington Ave, Boston, MA, USA. ${ }^{2}$ Center for Drug Evaluation and Research, U.S. Food and Drug Administration, Silver Spring, MD, USA.

${ }^{3}$ Department of Population Medicine, Harvard Medical School and Harvard Pilgrim Health Care Institute, Boston, MA, USA. ${ }^{4}$ Meyers Primary Care Institute (Fallon Community Health Plan, Reliant Medical Group, and University of Massachusetts Medical School), Worcester, MA, USA.

Received: 8 January 2019 Accepted: 18 November 2019

Published online: 27 November 2019

\section{References}

1. Albrecht SS, Kuklina EV, Bansil P, Jamieson DJ, Whiteman MK, Kourtis AP, et al. Diabetes trends among delivery hospitalizations in the U.S., 1994-2004. Diabetes Care. 2010;33(4):768-73.

2. Dabelea D, Snell-Bergeon JK, Hartsfield CL, Bischoff KJ, Hamman RF, McDuffie RS, et al. Increasing prevalence of gestational diabetes mellitus (GDM) over time and by birth cohort: Kaiser Permanente of Colorado GDM screening program. Diabetes Care. 2005;28(3):579-84.

3. Feig DS, Hwee J, Shah BR, Booth GL, Bierman AS, Lipscombe LL. Trends in incidence of diabetes in pregnancy and serious perinatal outcomes: a large, population-based study in Ontario, Canada, 1996-2010. Diabetes Care. 2014; 37(6):1590-6.

4. Getahun D, Nath C, Ananth CV, Chavez MR, Smulian JC. Gestational diabetes in the United States: Temporal trends 1989 through 2004. Am J Obstet Gynecol. 2008;198(5):525.e1-5.

5. Hayes DK, Fan AZ, Smith RA, Bombard JM. Trends in selected chronic conditions and behavioral risk factors among women of reproductive age, behavioral risk factor surveillance system, 2001-2009. Prev Chronic Dis. 2011; 8(6):A120.

6. Lawrence JM, Contreras R, Chen W, Sacks DA. Trends in the prevalence of preexisting diabetes and gestational diabetes mellitus among a racially/ ethnically diverse population of pregnant women, 1999-2005. Diabetes Care. 2008;31(5):899-904.

7. Kitzmiller JL, Block JM, Brown FM, Catalano PM, Conway DL, Coustan DR. Managing preexisting diabetes for pregnancy: summary of evidence and consensus recommendations for care. Diabetes Care. 2008;31(5):1060-79.

8. American College of Obstetricians and Gynecologists Committee on Practice Bulletins. ACOG Practice Bulletin. Clinical management guidelines for obstetrician-gynecologists. Number 30, September 2001. Gestational diabetes. Obstet Gynecol. 2001;98(3):525-38.

9. American College of Obstetricians and Gynecologists Committee on Practice Bulletins. ACOG Practice Bulletin No. 137: Gestational diabetes mellitus. Obstet Gynecol. 2013;122(2 Pt 1):406-16.

10. American Diabetes Association. (12) Management of diabetes in pregnancy. Diabetes Care. 2015;38(Suppl):S77-9.

11. American College of Obstetricians and Gynecologists Committee on Practice Bulletins. ACOG Practice Bulletin. Clinical Management Guidelines for Obstetrician-Gynecologists. Number 60, March 2005. Pregestational diabetes mellitus. Obstet Gynecol. 2005;105(3):675-85.

12. Behrman RE, Benner JS, Brown JS, McClellan M, Woodcock J, Platt R. Developing the sentinel system - a National Resource for evidence development. N Engl J Med. 2011;364(6):498-9.

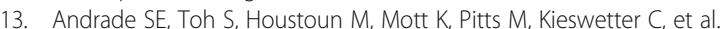
Surveillance of medication use during pregnancy in the mini-sentinel program. Matern Child Health J. 2016;20(4):895-903.

14. Andrade SE, Davis RL, Cheetham TC, Cooper WO, Li DK, Amini T, et al Medication exposure in pregnancy risk evaluation program. Matern Child Health J. 2012;16(7):1349-54

15. Kawai A, Li L, Kulldorff M, Hua W, Selvam N, McMahill-Walraven C, et al. Mini-Sentinel CBER/PRISM surveillance protocol: influenza vaccines and pregnancy outcome. Version 3.0 2017. Available from: sentinelinitiative.org

16. Li Q, Andrade SE, Cooper WO, Davis RL, Dublin S, Hammad TA, et al. Validation of an algorithm to estimate gestational age in electronic health plan databases. Pharmacoepidemiol Drug Saf. 2013;22(5):524-32.
17. Lawrence JM, Andrade SE, Avalos LA, Beaton SJ, Chiu WY, Davis RL, et al. Prevalence, Trends and Patterns of Use of Antidiabetic Medications Among Pregnant Women, 2001-2007. Obstet Gynecol. 2014;121(1):1-17.

18. Camelo Castillo W, Boggess K, Stürmer T, Brookhart MA, Benjamin DK, Jonsson FM. Trends in glyburide compared with insulin use for gestational diabetes treatment in the United States, 2000-2011. Obstet Gynecol. 2014; 123(6):1177.

19. Bardenheier BH, Imperatore G, Gilboa SM, Geiss LS, Saydah SH, Devlin HM, et al. Trends in gestational diabetes among hospital deliveries in 19 U.S. states, 2000-2010. Am J Prev Med. 2015;49(1):12-9.

\section{Publisher's Note}

Springer Nature remains neutral with regard to jurisdictional claims in published maps and institutional affiliations.
Ready to submit your research? Choose BMC and benefit from:

- fast, convenient online submission

- thorough peer review by experienced researchers in your field

- rapid publication on acceptance

- support for research data, including large and complex data types

- gold Open Access which fosters wider collaboration and increased citations

- maximum visibility for your research: over $100 \mathrm{M}$ website views per year

At $\mathrm{BMC}$, research is always in progress.

Learn more biomedcentral.com/submissions 